\title{
A (IN)JUSTIÇA DO PODER JUDICIÁRIO: O OBSTÁCULO ECONÔMICO DO ACESSO À JUSTIÇA E O DIREITO SOCIAL À SAÚDE
}

\author{
THE (IN)JUSTICE OF JUDICIAL POWER: THE ECONOMIC OBSTACLE TO ACCESS \\ TO JUSTICE AND THE SOCIAL RIGHT TO HEALTH
}

\author{
Juliana Zaganelli
}

\author{
Mestranda em Direitos e Garantias Fundamentais pela FDV - Faculdade de Direito de \\ Vitória. Membro do Grupo de Pesquisa, Estudos e Extensão em Políticas Públicas, Direito \\ à Saúde e Bioética (BIOGEPE). E-mail: julianazaganelli@gmail.com
}

Recebido em: 27/02/2016

Aprovado em: 25/04/2016

Doi: $10.5585 / \mathrm{rdb} . \mathrm{v} 15 \mathrm{i} 6.363$

\begin{abstract}
RESUMO: Ter acesso à justiça é um desejo e um direito de todo cidadão. Por isso, a intenção deste trabalho será tratar do acesso à justiça, além de destrinchar tanto os obstáculos desenvolvidos por Mauro Cappelletti e Bryant Garth (1988), quanto à "quarta onda" proposta por Kim Economides (1999). No caso em estudo, é demonstrado durante o III Seminário Justiça e Números, apresentado no dia 23 de setembro de 2010 por Alexandre dos Santos, que 63\% dos conflitos não chegam à justiça. Desse modo, será pormenorizado o obstáculo econômico, organizacional e processual do acesso à justiça de Cappelletti e Garth (1988), e, também, a quarta onda de Economides (1999), para que os indivíduos saibam a necessidade da efetivação dos direitos. Para se ter uma maior clareza acerca da discussão deste estudo, recorremos a apresentação de Alexandre dos Santos, representante do IPEA (Instituto de Pesquisa Econômica e Aplicada), sobre a dificuldade do acesso à justiça no Brasil, a qual é influenciada por fatores socioeconômicos. Portanto, a retórica surge nesse questionamento em que o acesso à justiça surge como um discurso vencedor colocando a justiça como essência do Poder Judiciário, enquanto ter acesso ao judiciário seja a mais cabal das injustiças.
\end{abstract}

Palavras-Chave: Acesso à justiça; Obstáculo Econômico; Retórica Jurídica.

ABSTRACT: Access to justice is a desire and a right of every citizen. Therefore, the intention of this paper will deal with access to justice, and tease out both obstacles developed by Mauro Cappelletti and Bryant Garth (1988), as the "fourth wave" proposed by Kim Economides (1999). In this particular case, it is demonstrated during the Third Seminar Justice and Numbers, presented on September 23, 2010 by Alexandre dos Santos that $63 \%$ of conflicts do not come to justice. Thus, it will be detailed economic obstacle, organizational and procedural access to justice Cappelletti and Garth (1988), and also the fourth wave of Economides (1999), for individuals to know the necessity of realization of rights. To have greater clarity about the discussion of this study, we used the presentation of Alexandre dos Santos, representative of IPEA (Applied Economic Research Institute), about the difficulty of access to justice in Brazil, which is influenced by socioeconomic factors. So the rhetorical question arises that where access 
to justice emerges as a winner speech putting justice as the essence of the judiciary, while having access to the judiciary is the most complete injustice.

Keywords: Access to Justice; Economic Obstacle; Legal Rhetoric.

SUMÁRIO: Introdução; 1. O Movimento Universal de Acesso à Justiça; 2. A Quarta "Onda" do Acesso à Justiça de acordo com Kim Economides: A ética como um caminho além das Três "Ondas" de Acesso à Justiça de Cappelletti e Garth; 3. O Acesso à Justiça e os obstáculos do Movimento Universal de Cappelletti e Garth: A questão econômica e o embate com o princípio da igualdade; 4. O Poder Judiciário como (in)justiça: a retórica do obstáculo econômico de Acesso à Justiça e o enfrentamento pela efetividade do Direito Social à Saúde; Conclusão; Referências.

\section{INTRODUÇÃO}

Todos os cidadãos devem ter acesso à justiça, em especial por se tratar de um direito assegurado pela própria Constituição Brasileira. No entanto, tal acesso é restrito e não são todos os indivíduos que o conseguem ter.

Além disso, a parcela populacional que consegue se apropriar desse acesso, não necessariamente, a justiça é alcançada, o que demonstra uma relação complicada, pois ao mesmo tempo em que se tem acesso, não se tem justiça, em muitos casos.

Para isso, será analisado no primeiro momento, os obstáculos desenvolvidos por Mauro Cappelletti e Bryant Garth (1988) e, posteriormente a "quarta onda" proposta por Kim Economides (1999). No terceiro momento, será apresentado o embate da questão econômica com o princípio da igualdade, no que tange o acesso à justiça.

Por fim, o estudo em tela irá ater-se a questão do Poder Judiciário como (in)justiça, de modo a enfrentar a efetividade do direito social à saúde. Para tanto, será demonstrado um estudo apresentado no III Seminário Justiça e Números, em que retrata a realidade de $63 \%$ dos conflitos não chegam à justiça.

Portanto, em que medida o Poder Judiciário pode ser considerado um sinônimo de justiça no que tange o obstáculo econômico do acesso à justiça e o direito social à saúde?

\section{O MOVIMENTO UNIVERSAL DE ACESSO À JUSTIÇA}

O projeto florentino, de acordo com foi financiado pela Ford Fundation, o Consiglio Nazionale delle Recerche e o Centro Florentino do Stuti Giudiziari Comparati (SANTOS, 2008, p. 67). Com a participação de vários estudiosos representantes de diversos países, esse projeto teve como escopo maior identificar as causas e efeitos dos obstáculos que proporcionam a precariedade do acesso à justiça, além de estabelecer as chamadas "ondas" com o intuito de amenizar os três obstáculos: o econômico, o organizacional e o processual.

Em razão disso, cabe explicar os três obstáculos ao acesso efetivo à justiça, identificados por Cappelletti e Garth (1988). O primeiro é o econômico, caracterizado pela pobreza, falta de informação de direito e deveres dos cidadãos, representação inadequada, dentre outros fatores que, por sua vez, são verificados por motivos socioeconômicos, o que implica na baixa possibilidade de acesso dos cidadãos pobres à justiça.

Na sequência, o obstáculo organizacional, o segundo do movimento universal de acesso à justiça, apresenta como problema básico a representação e proteção dos direitos e interesses 
difusos - tais como, o direito ao meio ambiente ou do consumidor -, que são desamparados de proteção por legislações.

Inclusive, Bobbio salienta que "o problema fundamental em relação aos direitos do homem, hoje, não é tanto o de justificá-los, mas o de protegêe-los. Trata-se de um problema não filosófico, mas político" (2004, p. 42). Com isso, o foco não deve estar na quantidade ou na natureza dos problemas e, sim, na garantia desses direitos para que sejam protegidos, e não violados.

Já o terceiro obstáculo do movimento universal de reforma, o processual, dispõe de diversos entraves, tais como, a morosidade do processo, a sobrecarga no sistema judicial, o formalismo exacerbado, a falta de juízes e gestão, os quais dificultam a efetividade nas resoluções de conflitos. Em suma, é fundamental analisar as barreiras envolvidas para que essas sejam amenizadas, o que contribuirá para que o acesso à justiça seja mais amplo, efetivo e disponível a uma grande parcela da população.

Por conta disso, Mauro Cappelletti e Bryant Garth romperam com o tradicional racionalismo do sistema jurídico-processual. A partir disso, as "ondas" ingressaram como propostas de amenização dos obstáculos, pois Cappelletti e Garth lecionam que a erradicação total desses é pura utopia (CAPPELLETTI; GARTH, 1988). Nesse aspecto, Cappelletti e Garth aludem que:

Podemos afirmar que a primeira solução para o acesso - a primeira "onda" desse movimento novo - foi à assistência jurídica; a segunda dizia respeito às reformas tendentes a proporcionar representação jurídica para os interesses "difusos", especialmente nas áreas da proteção ambiental e consumidor; e o terceiro - e mais recente - é o que podemos chamar simplesmente de "enfoque de acesso à justiça" porque inclui os posicionamentos anteriores, mas vai muito além deles, representando, dessa forma uma tentativa de atacar as barreiras do acesso de modo mais articulado e compreensivo (CAPPELLETTI; GARTH, 1988, p. 31).

À luz desse contexto é possível constar as “ondas” do movimento universal de acesso à justiça, projeto que trouxe a compreensão do tema relacionado, introduzidas por Mauro Cappelletti e Bryant Garth, no livro acesso à justiça, do ano de 1988.

\section{A QUARTA "ONDA" DO ACESSO À JUSTIÇA DE ACORDO COM KIM ECONOMIDES: A ÉTICA COMO UM CAMINHO ALÉM DAS TRÊS “ONDAS” DE ACESSO À JUSTIÇA DE CAPPELLETTI E GARTH}

Além das três ondas de Mauro Cappelletti e Bryant Garth é interessante tratar a quarta onda do movimento de acesso à justiça por meio do ensinamento de Kim Economides.

Para Kim Economides, o acesso à justiça está além das três “ondas" estabelecidas por Cappelletti e Garth, apesar de serem extremamente importantes para o desenvolvimento do tema: acesso à justiça.

Nesse mesmo sentido, Kim Economides ressalta o fato de que a ética profissional deve estar no centro do debate, pois o problema não está somente relacionado ao acesso dos cidadãos à justiça, mas também dos operadores do direito à justiça, que é indispensável (ECONOMIDES, 1999, p. 62-63).

Nessa polaridade, o estudioso destaca duas áreas: de um lado, a primeira é a metodologia, o autor explica que para se entender essa área, é necessário compreender três elementos, dos quais são: “a) a natureza da demanda dos serviços jurídicos; b) a natureza da 
oferta desses serviços jurídicos; e c) a natureza do problema jurídico que os clientes possam desejar trazer ao fórum da justiça" (ECONOMIDES, 1999, p. 62-64).

Mais que isso, a precariedade ao acesso à justiça, não é necessariamente explicado somente pelo fato da "pobreza" propriamente dita, mas também pela falta de informação, consciência, vontade, medo de ir aos tribunais ou devido à distância física, há, portanto, diversos fatores envolvidos para os indivíduos não ingressarem à justiça.

Diante disso, Kim Economides realça que "a natureza e o estilo dos serviços jurídicos oferecidos são, portanto, fatores cruciais que influenciam, quando não determinam, a mobilização da lei” (ECONOMIDES, 1999, p. 67). Nessa visão, é inegável que se houvesse um aperfeiçoamento nos serviços jurídicos prestados de forma a incentivar o acesso ao direito, provavelmente, o acesso dos cidadãos à justiça iria melhorar. Por outro lado, a segunda área que Economides inclui é a epistemologia (ECONOMIDES, 1999, p. 69). Nessa parte, o acesso à justiça está vinculado aos temas de cidadania e de constitucionalismo, o que reforça o Estado de Direito.

Além disso, os indivíduos que buscam obter privacidade e celeridade processual, principalmente, optam por processos alternativos de resolução de conflitos, pois esses tem como foco o objeto do processo e desconsideram de certa forma o formalismo e a técnica processual. Acresça-se que Economides se preocupa, também, com o demasiado informalismo judicial, porque esse pode negar valores, além de não fornecer segurança jurídica como em atos processuais que são formalísticos (ECONOMIDES, 1999, p. 71).

Com isso, Kim Economides revela uma "quarta onda" do movimento de acesso à justiça, a que centraliza a ética e a política da administração da justiça, o que proporciona desafios nos campos da responsabilidade profissional e do ensino jurídico, assim, nota-se que não somente os cidadãos devem ter acesso à justiça, mas também, os operadores do direito (ECONOMIDES, 1999, p. 72).

Por conseguinte, no que tange a oferta do acesso dos cidadãos à justiça, Economides destaca dois níveis distintos: "primeiro o acesso dos cidadãos ao ensino do direito e ao ingresso nas profissões jurídicas; segundo, uma vez qualificados, o acesso dos operadores do direito à justiça” (ECONOMIDES, 1999, p. 73).

Sob essa análise, entende-se que o primeiro abrange as faculdades de direito por serem, como o autor realça "as guardiãs dos portões de acesso à carreira jurídica”, já a segunda desenvolve um estudo do campo da ética legal.

Em razão disso, para Kim Economides, as faculdades de direito deveriam adotar matérias sobre os direitos humanos, por serem essenciais tanto para a cidadania, quanto para o futuro profissional do direito.

\section{O ACESSO À JUSTIÇA E OS OBSTÁCULOS DO MOVIMENTO UNIVERSAL DE CAPPELLETTI E GARTH: A QUESTÃO ECONÔMICA E O EMBATE COM O PRINCÍPIO DA IGUALDADE}

“A justiça sem força e a força sem justiça: desgraças terríveis” (JOUBERT, 2011, p. 25). $\mathrm{O}$ acesso à justiça é fundamental para que os direitos dos indivíduos não sejam violados. Entretanto, um acesso que deveria ser para todos os cidadãos de forma equitativa, para alguns é restrito por conta de fatores socioeconômicos.

Por isso, conforme Karl Marx, a igualdade é apenas formal, expressa na lei e não na realidade social, exemplo disso seria que a morosidade processual acarreta em altos custos, o que reflete no baixo acesso de uma classe abastada à justiça, consequentemente, os direitos dessa classe serão lesados e não ressarcidos (MARX; ENGELS, 2008). Para Marx, o poder de dominação é que desencadeia as desigualdades, pois a economia, influenciada pela classe 
dominante, além de ser o fundamento de explicação da realidade social, segrega as classes(MARX; ENGELS, 2008). Dessa forma, a classe subjacente é sufocada pela dominante, o que é visto no difícil acesso dos cidadãos pobres à justiça por conta, principalmente, da desigualdade entre essas.

Pelo exposto, o Conselho Nacional de Justiça (CNJ) e o Instituto de Pesquisas Econômicas Aplicadas (IPEA) divulgaram uma estimativa apresentada no dia 23 de setembro de 2010 pelo representante do IPEA, Alexandre dos Santos, durante o III Seminário Justiça em Números, promovido pelo CNJ em Brasília, Distrito Federal, a qual dispôs que $63 \%$ dos conflitos não chegam à justiça.

O intuito da apresentação feita por Alexandre dos Santos era de demonstrar o número de processos que ingressaram à justiça no ano de 2009, o qual poderia ter sido $170 \%$ maior, além de o representante do IPEA ressalvar que grande parte da dificuldade ao acesso à justiça é devido à fatores socioeconômicos, como renda e escolaridade.

Cabe enfatizar ainda que se houvesse o aumento de pelo menos um ano na escolaridade média da população de um estado brasileiro, aumentaria a demanda por serviços judiciários em 1.182 processos novos a cada 100 mil habitantes por ano, como é afirmado na notícia do CNJ e do IPEA. A partir disso, pode ser observado no quadro abaixo o número de casos novos, em 2009, por Unidade da Federação

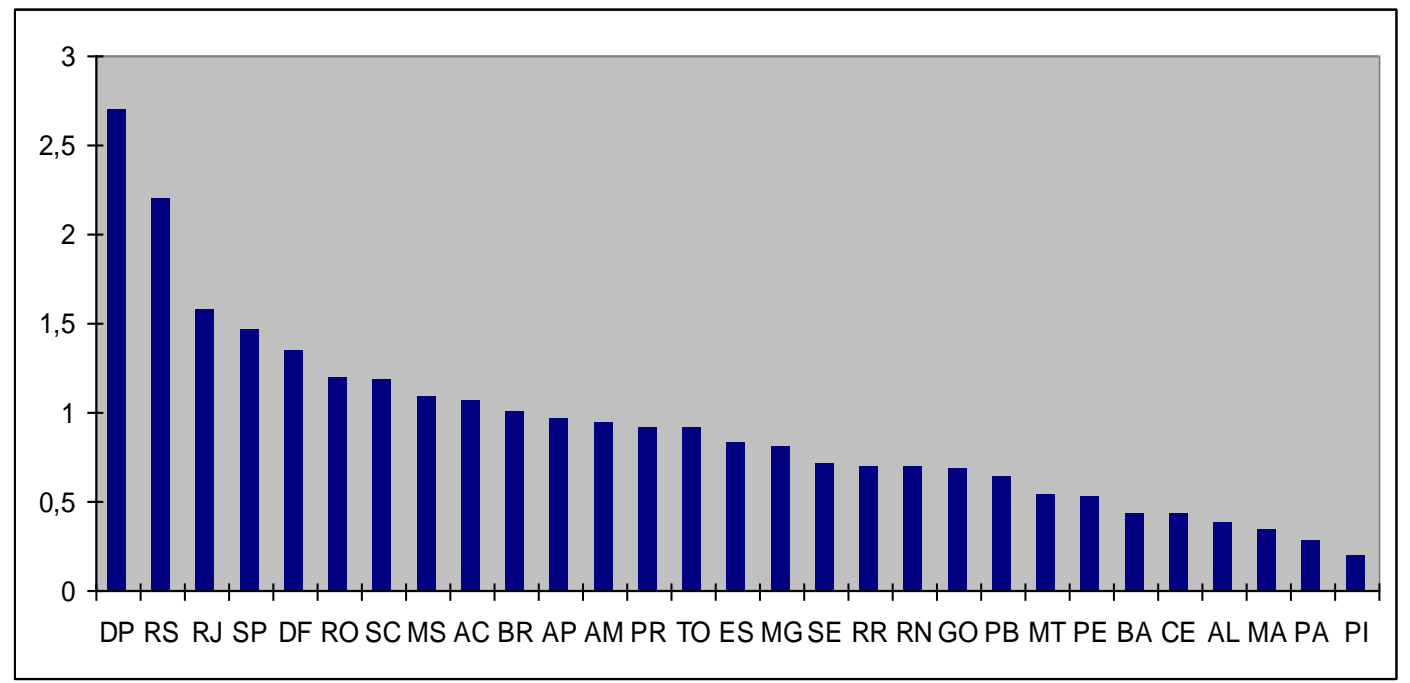

Fonte: SANTOS, 2010.

É possível observar no gráfico acima o número de novos casos levados ao judiciário por cada estado brasileiro e que há uma baixa demanda dos estados localizados, principalmente, no nordeste. O que é visualizado na tabela abaixo: 


\begin{tabular}{|l|l|l|l|l|}
\hline Quartil & $\begin{array}{l}\text { Unidade da } \\
\text { Federação }\end{array}$ & $\begin{array}{l}\text { Casos } \\
\text { novos } \\
\text { (CNJ, 2010) }\end{array}$ & $\begin{array}{l}\text { Anos de } \\
\text { estudo } \\
\text { (IPEA, 2007) }\end{array}$ & $\begin{array}{l}\text { Percentual } \\
\text { de pobres } \\
\text { (IPEA, 2000) }\end{array}$ \\
\hline Primeiro & $\begin{array}{l}\text { RS, RJ, SP, } \\
\text { DF, RO, SC } \\
\text { e MS }\end{array}$ & 1,43 & 7,52 & 19,55 \\
\hline Segundo & $\begin{array}{l}\text { AC, AP, AM, } \\
\text { PR, TO, ES } \\
\text { e MG }\end{array}$ & 0,92 & 6,81 & 39,43 \\
\hline Terceiro & $\begin{array}{l}\text { SE, RR, RN, } \\
\text { GO, PB, MT } \\
\text { e PE }\end{array}$ & 0,64 & 6,12 & 43,08 \\
\hline $\begin{array}{l}\text { BA, CE, AL, } \\
\text { MA, PA e PI }\end{array}$ & 0,34 & 5,33 & 59,18 \\
\hline
\end{tabular}

Fonte: SANTOS, 2010.

Diante da tabela apresentada acima, a litigiosidade, a educação e a pobreza influenciam no acesso dos cidadãos à justiça, de acordo com a apresentação de Alexandre dos Santos, representante do IPEA, 53,54\% da demanda pode ser justificada pelos níveis de educação e de pobreza (CNJ, 2010).

Por isso, cabe reforçar ainda que o movimento de acesso à justiça possui três obstáculos: o econômico, o organizacional e o processual. Contudo, será realçado abaixo, o econômico. O primeiro obstáculo do movimento de acesso à justiça, introduzido por Mauro Cappelletti e Bryant Garth, iniciado no ano de 1965, tem como enfrentamento a pobreza que por motivos econômicos, não há, também, acesso à informação e à representação adequada, como garante Ricardo Goretti Santos (2008, p. 69).

Ademais, Cappelletti, em seu livro "acesso à justiça", afirma que "[...] qualquer tentativa realística de enfrentar os problemas de acesso deve começar por reconhecer essa situação: os advogados e seus serviços são muito caros" (1988, p. 18). Com efeito, é possível perceber a extrema dificuldade que indivíduos com baixo poder aquisitivo enfrentam a partir do quadro apresentado por Mauro Cappelletti, pois, além de não possuírem o devido acesso à informação e a representação adequada, quando ao judiciário enfrentam a outra parte sem a presença da igualdade.

Vale ressaltar que, apesar da formalidade processual ser indispensável para promover a segurança jurídica, ao ser esta exacerbada, o objeto do processo é esquecido perante a técnica e o formalismo.

Além do mais, ao momento em que o tempo de duração dos processos passa a ser longo, devido ao formalismo exagerado do sistema judicial, os custos para as partes litigantes aumentam, o que desencadeia em uma desigualdade ainda maior entre essas em situações de uma delas ter um poder aquisitivo baixo, segundo o pensamento de Ricardo Goretti Santos (2008, p. 69). Pode-se conferir, por meio do caso abordado que os fatores socioeconômicos influenciam o acesso dos hipossuficientes ou das pessoas com baixo poder aquisitivo à justiça.

Dessa forma, nota-se que o princípio da inafastabilidade consagrado no artigo 5, inciso XXXV, da Constituição Federal de 1988, que expõe: "a lei não excluirá da apreciação do Poder Judiciário lesão ou ameaça de direito", deve ser questionado, pois, a partir do momento em que o Judiciário impõe barreiras como no caso do moroso processo judicial que acarreta em um alto custo, além de não se ter uma devida assistência aos que necessitam de tal recurso, por possuir baixa renda, está afastando as pessoas de enfrentar um processo judicial e de reivindicar seus direitos fundamentais.

Nesse sentido, consoante Ricardo Goretti Santos a partir da lei n. 1060, de 1950, que leciona: "De fato, a gratuidade das custas processuais e dos honorários advocatícios é pressuposto 
indispensável para a efetivação do acesso ao Judiciário pelos jurisdicionados considerados pobres nos termos da lei" (SANTOS, 2008, p. 61). A partir disso, conforme dispõe à primeira onda, é fato que deve ser aperfeiçoada a implantação das assistências judiciárias, integrais e gratuita aos pobres, com isso, o acesso desses cidadãos pobres nos termos da lei à justiça seria mais efetivo.

Entretanto, na realidade não basta somente existir assistências judiciárias, essas devem ser eficientes, pois, caso não, provoca com que os desfavorecidos acatem propostas injustas feitas pelos economicamente mais fortes, de acordo com os termos do direito (SANTOS, 2008a, p. 69).

Diante dos fatos, Cappelletti ofereceu três sistemas de prestação destes serviços para serem avaliados na pesquisa: o sistema judicare; o do advogado remunerado pelos cofres públicos; e o modelo combinado. $\mathrm{O}$ primeiro tem como finalidade remunerar, pelo Estado, os advogados particulares, o que irá proporcionar aos litigantes de poder aquisitivo baixo, nos termos da lei, a igual representação que obteriam se pudessem pagar um advogado particular (CAPPELLETTI; GARTH, 1988, p. 35).

Por sua vez, o segundo, tem como escopo fazer com que os advogados remunerados pelo Estado, em seus "escritórios de vizinhança", promovam a defesa dos interesses dos indivíduos de baixa renda, enquanto classe. Esse segundo sistema é mais vantajoso do que o primeiro, o judicare, por "apoiar os interesses difusos ou de classe das pessoas pobres" (CAPPELLETTI; GARTH, 1988, p. 40). A respeito do mesmo assunto, acrescenta Cappelletti e Garth que:

As vantagens dessa sistemática sobre o judicare são óbvias. Ela ataca outras barreiras ao acesso individual, além dos custos, particularmente os problemas derivados da desinformação jurídica pessoal dos pobres. Ademais, ela pode apoiar os interesses difusos ou de classes das pessoas pobres. [...] Em suma, além de apenas encaminhar as demandas individuais dos pobres que são trazidas aos advogados, tal como no sistema judicare, esse modelo norte-americano: 1) vai em direção aos pobres para auxiliá-los a reivindicar seus direitos e 2) cria uma categoria de advogados eficientes para atuar pelos pobres, enquanto classe (1988, p. 40).

Finalmente, o terceiro sistema foi denominado como modelo combinado - devido ao fato dos dois modelos de assistência jurídica serem combinados - o qual proporcionou que tanto as pessoas desfavorecidas, quanto os pobres como grupo, puderam ser beneficiados (CAPPELLETTI; GARTH, 1988, p. 44). Assim, foram disponibilizados aos pobres os serviços jurídicos de advogados particulares e de servidores públicos. Nesse contexto, é válido observar que esses sistemas que englobam a primeira onda do movimento de acesso à justiça não irão erradicar totalmente os efeitos dos problemas que estão relacionados ao obstáculo econômico, e sim amenizá-los.

Além desse fator, a importância dos serviços jurídicos prestados aos pobres, como alude Ricardo Goretti Santos (2008, p. 71), se choca as questões orçamentárias, exemplo disso é a falta de profissionais qualificados e disponíveis para auxiliar os que não podem suprir os custos dos serviços. Sob esse fato, Mauro Cappelletti e Bryant Garth advertem que:

A assistência judiciária, no entanto, não pode ser o único enfoque a ser dado pela reforma que cogita do acesso à Justiça. Existem limites sérios na tentativa de solução pela assistência judiciaria. Antes de mais nada, para que o sistema seja eficiente, é necessário que haja um grande numero de advogados, um numero que pode ate exceder a oferta, especialmente em países em desenvolvimento, Em segundo lugar, mesmo presumindo que haja advogados em numero suficiente, no país, é preciso que eles se tornem disponíveis para auxiliar aqueles que não podem pagar por seus serviços. Isso faz necessárias Revista de Direito Brasileira | São Paulo, SP | v. 15 | n. 6 | p. 185 - 199 | set./dez. 2016 
grandes dotações orçamentárias, o que é problema básico dos esquemas de assistência judiciaria (1988, p. 47).

É possível constatar que Cappelletti e Garth estão conscientes de que são necessárias grandes medidas de natureza orçamentária para se ter um alto número de advogados disponíveis, no que tange à assistência daqueles que não podem custear os serviços, especialmente, em países subdesenvolvido e em desenvolvimento, como no caso do Brasil, país o qual dispõe de grande desigualdade social.

Posto isso, não basta constar na Constituição Federal do Brasil em seu artigo 5, LXXIV, que "o Estado prestará assistência integral e gratuita aos que comprovarem a insuficiência de recursos" (BRASIL, 1988), integrando a Defensoria Pública - uma instituição desprovida de recursos, apesar de ser uma forma de amenização do obstáculo econômico -, deve-se efetivar esses artigos constitucionais, principalmente, os que são fundamentais, ao torná-los legítimos e efetivos, para se ter um país de igualdade, um país democrático na realidade.

Embora, cabe complementar que ao momento o qual o Estado procura através de ações, orientar e fornecer assistência jurídica de forma integral e gratuita aos pobres nos termos da lei, esses devem requerer isto e assinar um termo para declarar a falta de recursos. Como se vê, o obstáculo econômico implica a divisão de classes, isto é, no distanciamento entre os que não possuem um poder monetário alto e os ricos, o que ocasiona não só a desigualdade social, mas também, a desigualdade acadêmica e a processual. Em virtude disso, José Murilo de aduz que:

Do ponto de vista da garantia dos direitos civis, os cidadãos brasileiros podem ser divididos em classes. Há os de primeira classe ou "doutores", que estão acima da lei, que sempre conseguem defender seus interesses pelo poder do dinheiro e do prestígio social. Os doutores são invariavelmente brancos, ricos, bem vestidos com formação universitária. São empresários, banqueiros, grandes proprietários rurais e urbanos, políticos, profissionais liberais, altos funcionários. Frequentemente, mantém vínculos importantes nos negócios, no governo, no próprio Judiciário. Esses vínculos permitem que a lei só funcione em seu benéfico. [...] Ao lado dessa elite privilegiada, existe uma grande massa de "cidadãos simples", de segunda classe, que estão sujeitos aos rigores e benefícios da lei [...]. Essas pessoas nem sempre tem noção exata de seus direitos, e quando a tem carecem dos meios necessários para os fazer valer, como o acesso aos órgãos e autoridades competentes e os recursos para custear demandas judiciais [...]. Para eles, existem os códigos civil e penal, mas aplicados de maneira parcial e incerta. Finalmente, há os "elementos" do jargão policial, cidadãos de terceira classe. São a grande população marginal das grandes cidades, trabalhadores urbanos e rurais sem carteira assinada, posseiros, empregadas domésticas, biscateiros, camelôs, menores abandonados, mendigos [...]. Na prática, ignoram seus direitos civis ou os têm sistematicamente desrespeitados por outros cidadãos, pelo governo, pela policia. Não se sentem protegidos pela sociedade e pelas leis [...]. Para eles vale apenas o Código Penal (CARVALHO, 2005, p. 215-217).

Dessa perspectiva, nota-se que "falta o exercício efetivo do Império da Lei, que é pressuposto de um estado democrático de direito" (SANTOS, 2008, p. 114), isto é, falta autoridade do Poder Público que, em vez de adequar a lei ao caso concreto de forma imparcial, utiliza o poder e o cargo para permitir com que a lei não funcione efetivamente para os "doutores" da "primeira classe", principalmente, o que demonstra a falta de ética profissional.

Outrossim, vale perceber que a educação é fundamental, porque quem adquire um bom ensino e uma profissão consegue informação, o que proporciona um conhecimento dos direitos e 
deveres, além de incitar a empregabilidade. Contudo, o que se vê no caso concreto é um baixo acesso à justiça de indivíduos financeiramente carentes e desprovidos de informação sobre seus direitos.

É inegável, então, perceber que a educação tem relação com o sistema econômico, o que demonstra a necessidade de não só investir em defensoria pública, mas também em educação para proporcionar com que as pessoas procurem o meio judiciário ou métodos alternativos para reivindicar seus direitos e adquiri-los de forma correta e efetiva. Todavia, o essencial seria investir no aperfeiçoamento do setor educacional, o qual implicaria um incentivo da própria cultura local, além de que as oportunidades educacionais podem reduzir o valor das credenciais, pois, como explica Simon Schwartzman:

Quando as credenciais são mais importantes do que as competências efetivas das pessoas, não há incentivo para melhorar a qualidade da educação, que se transforma em um ritual burocrático e formalista, ao fim do qual as credenciais certificados, diplomas - são distribuídas (SIMON, 2004, p. 152).

Nessa convicção, apesar de existir fortes indícios de que a desigualdade social é consequência da falta de educação, é, também, gerada pela falta de oportunidades de trabalho, de incentivos por conta dos governos e de melhoria na qualidade do setor educacional, para valorizar as competências das pessoas e não somente as credenciais dessas.

É proveitoso esclarecer que, apesar dos fatores multicausais, os quais comprometem o acesso à justiça - a falta de aspectos primordiais, tais como, o financeiro, a informação, a geografia, a representação inadequada, a falta de recursos humanos, a parcialidade no sistema, dentre outros. -, é fundamental que haja meios de amenização dessas barreiras, porque ter acesso à justiça é ter acesso a um direito que foi negado.

Sendo assim, a notícia do Conselho Nacional de Justiça (CNJ) e do Instituto de Pesquisas Econômicas Aplicadas (IPEA), demonstra que o acesso à justiça é restrito, o que não deveria ocorrer, pois, proporciona segurança aos indivíduos que regem uma sociedade, nas relações de uns com os outros, para que seus direitos sejam resguardados e, dessa maneira, é fundamental que se insira um planejamento efetivo e equitativo nesse setor para que seja mais amplo o acesso de todos os cidadãos à justiça.

Portanto, é indispensável o acesso à justiça e, por conta disso deve haver a implantação de formas de amenização, tais como, o incentivo à educação e a informação, além da representação adequada para que os indivíduos de baixa renda também possam requerer seus direitos de forma equitativa.

\section{O PODER JUDICIÁRIO COMO (IN)JUSTIÇA: A RETÓRICA DO OBSTÁCULO ECONÔMICO DE ACESSO À JUSTIÇA E O ENFRENTAMENTO PELA EFETIVIDADE DO DIREITO SOCIAL À SAỬE}

A retórica é uma arte que se utiliza da linguagem para persuadir de modo eficaz, desvelando para a audiência o logos (que), o pathos (quem) e o ethos (como), diante disso, tudo se revela relativo, não havendo uma verdade absoluta. Mas, além de tudo é uma abordagem filosófica que se ocupa, nesse trabalho sobre a questão da justiça.

Não sendo necessariamente ligada a questão do bem, de acordo com Aristóteles, mas a retórica se expressa como qualquer forma de persuasão. João Maurício Adeodato demonstra que:

Essas três expressões são utilizadas na Retórica de Aristóteles como meios de persuasão na comunicação e compõem a auto-apresentação dos oradores: "a 
primeira espécie depende do caráter pessoal do orador; a segunda, de provocar no auditório certo estado de espírito; a terceira, da prova, ou aparente prova, fornecida pelas palavras do discurso propriamente dito" [...].Em Aristóteles é colocada claramente a junção entre retórica e virtude moral, fazendo o ethos acompanhar a virtude (areté) e a ponderação ou prudência (phorónesis), muito embora o caráter necessário dessa correlação tenha sido questionado desde o início, debatendo os eruditos sobre diferentes critérios para separação conceitual entre ethos, areté e phorónesis. Da mesma maneira que Aristóteles insiste para que a retórica não possa ser usada sem uma boa ética, opiniões contrárias vêem a retórica como um instrumento para quaisquer fins. Exatamente a presença dessa controvérsia atesta o problema da relação milenar entre retórica e ethos (ADEODATO, 2009, p. 20-21).

O acesso à justiça era percebido como um acesso aos tribunais, ao Poder Judiciário, de forma igualitária e universal em um Estado Democrático de Direito, como bem retrata a Constituição Federal de 1988. Contudo, apesar de elevar a justiça como um de seus valores, tendo o acesso ao judiciário como forma de efetivar tal justiça diante um conflito, não é o que está ocorrendo, pelo contrário.

A gratuidade da via judiciária é algo bastante romântico por meio da perspectiva econômica da sociedade brasileira, uma vez que o Judiciário se revela a atender uma parcela mais restrita da população e o povo passa a se frustrar com a justiça almejada em 1988.

E é nesse ponto que a retórica reside, tendo em vista que de um lado há uma tranquilidade em afirmar a garantia do acesso à justiça para todos, mediante o Texto Constitucional, mas que tais indivíduos, apesar de ingressarem ao judiciário para "em tese" fazer justiça, deverão arcar com custo-tempo. Além disso, há que se mencionar a distância da linguagem que esses sujeitos sofrem ao entrarem no Poder Judiciário.

João Maurício Adeodato leciona que: "Na terminologia de Gehlen, o ser humano ora é visto pela antropologia filosófica como um ente rico ou pleno (reiches Wesen), ora como um ente pobre ou carente (armes Wesen), segundo suas relações com o meio circundante" (ADEODATO, 2009, p. 16).

Então, há sempre uma modificação, uma mudança de perspectiva que acaba por excluir determinada parcela da sociedade no alcance de direitos fundamentais por meio do Poder Judiciário, local ao qual se pensa que se fará a verdadeira justiça.

Ou seja, não são todos que possuem essa oportunidade de ter acesso à justiça, tampouco ter a efetivação de seus direitos, tendo em vista, principalmente, o fator econômico. Por exemplo, é inegável a diferença entre um trabalho de um advogado dativo e um advogado contratado, sendo isso ainda mais um caracterizador da discrepância entre o tratamento de uns para outros, levando o acesso à justiça ser algo classista e não de origem universal e igualitária, como deveria ser. Além do mais, como se percebe,

A estratégia política do judiciário tem sido casuística, na medida em que as fundamentações têm variado a ponto de ser difícil seguir um vetor qualquer de racionalidade para unificação da jurisprudência em geral, aí incluída a jurisdição constitucional (ADEODATO, 2009, p. 154).

Ainda, cabe mencionar que:

Com efeito, o homem injusto julga que é poderoso e feliz porque faz tudo o que quer. Entretanto, uma longa discussão, no "Górgias" (466 e; 479 b), mostra que, como o fim perseguido por todo homem é o bem e a injustiça traz apenas o mal 
(mais ainda para quem a pratica do que para quem a sofre), quem é injusto na verdade faz o que não quer: procurando o próprio bem, encontra apenas o mal. Uma tal situação, longe de ser manifestação de poder e produzir felicidade, revela fraqueza e produz sofrimento (SILVA, 2015, p. 86).

Ademais, o acesso à justiça não deve ser confundido com o acesso aos Tribunais, uma vez que por mais que tais indivíduos consigam ingressar no Poder Judiciário, muitas vezes não conseguirão ter seu direito garantido, o que não caracteriza, também, o alcance da tão almejada justiça. Assim,

Esse crescimento de seu papel não significa que o judiciário se venha se mostrando à altura da sobrecarga, muito pelo contrário. Mesmo em países com menos problemas estruturais do que o Brasil, juristas e filósofos como Ingeborg Maus vêm clamando sobre o perigo de uma "moral do judiciário" e advertindo sobre a inviolabilidade de este poder exercer o papel de "superego da sociedade órfã". [...] O crescimento mais recente de mediação, arbitragem e outros procedimentos extrajudiciais de controle de conflitos também aponta para as disfunções que atormentam os que precisam da atuação do judiciário. [...] Assim, a ineficácia judicial conduz a uma crise de legitimação do judiciário, decorrente tanto de fatores internos - como o anacronismo de sua estrutura organizacional e o despreparo de seus agentes - como de fatores externos como a insegurança da sociedade em relação a impunidade, corrupção, discriminação e aplicação seletiva das normas jurídicas (ADEODATO, 2009, p. $165)$.

Desse modo, no que se refere o direito à saúde, sendo um direito fundamental, este não pode ser reduzido a mera interpretação da lei. É inegável que a importância do Judiciário na comprovação e na garantia dos direitos, mas em muitos casos, somente à a simples integração da lei ao fato, sendo que sequer tal fato é analisado por meio de peritos e outros auxiliares para cumprir seu papel de forma efetiva.

A saúde não é simplesmente uma situação de não doença, mas sim, de qualidade de vida e deve ser encarada em todas suas nuanças pelo Poder Judiciário, para também, assegurar a dignidade e outras garantias constitucionais. Contudo, não há efetividade em muitos casos, por conta da superlotação de processos ou por descaso até mesmo, exemplo disso, é a concessão de liminar para a realização de uma cirurgia em um idoso com diversos outros problemas.

Nesse ponto haveria qualidade de vida? Haveria a preservação da dignidade ao ser este idoso transferido para uma Unidade de Tratamento Intensivo após a cirurgia e falecer longe de seus familiares? Não seria mais efetivo o direito à saúde se não fosse considerado todo o seu quadro e concluir pela não concessão da liminar? Isso não iria efetivar mais o direito à saúde desse cidadão? E quando o Poder Judiciário

Esses questionamentos demonstra que por mais que seja correto conceder a liminar para assegurar à saúde e a oportunidade de melhora do quadro do indivíduo, não garante o acesso ao direito fundamental, tendo em vista o quadro de instabilidade do corpo daquele ser humano que não aguentaria uma cirurgia e poderia sobreviver um pouco mais do lado de seus familiares.

A saúde tornou-se um bem altamente comerciável, por conta do sistema capitalista, fazendo com que médicos fiquem ricos em detrimento do sofrimento alheio. Com o intuito muitas vezes de se fazer uma cirurgia ou conceder um medicamento caro "essencial" para a recuperação, muitas vezes não o é. O repórter Giovani Grizotti, fez uma investigação pelo Fantástico que demonstrou que:

Máfia das próteses coloca vidas em risco com cirurgias desnecessárias Médicos Revista de Direito Brasileira | São Paulo, SP | v. 15 | n. 6 | p. 185 - 199 | set./dez. 2016 
chegam a faturar R $\$ 100$ mil por mês em esquema que desvia dinheiro do SUS e encarece planos de saúde. Já imaginou médicos que mandam fazer cirurgias de próteses sem necessidade, só para ganhar comissão sobre o preço desses implantes? Ou então gastar muito mais material do que o necessário, também para faturar um dinheiro por fora? [...]Empresas que vendem próteses oferecem dinheiro para que médicos usem os seus produtos. Mercado de próteses movimenta anualmente R\$ 12 bilhões no Brasil (GLOBO, 2015).

O Tribunal de Justiça de Goiás revelou que o médico urologista Pedro Alves de Abreu Filho realizou um procedimento cirúrgico desnecessário em 2000 para desobstrução de ureter:

EMENTA: APELAÇÃO CÍVEL. AÇÃO DE INDE-NIZAÇÃO POR DANO MORAL. RECURSO ADE-SIVO. AGRAVO RETIDO. ERRO MÉDICO. REA-LIZAÇÃO DE PROCEDIMENTO CIRÚRGI-CO DESNECESSÁRIO PARA DESOBSTRUÇÃO DE URÉTER EM PACIENTE QUE SOFRE DE AGE-NESIA RENAL (AUSÊNCIA DO RIM ESQUER-DO). CONDUTA NEGLIGENTE E IMPRUDENTE DEMONSTRADA. VALOR DA INDENIZAÇÃO MANTIDO. 1. Não se conhece de agravo retido quando o agravante deixa de requerer a sua apreciação nas razões do recurso interposto ao Tribunal 2. A responsabilidade do médico, en-quanto profissional liberal, é subjetiva, vale dizer, para a sua caracterização, deve ficar demonstra-da a conduta culposa do profissional (art. 14, $\S 4^{\circ}, \mathrm{CDC}$ ), além do nexo causal entre essa conduta e o alegado dano sofrido pelo paciente. 3. Age com culpa o médico urologista que submete o pa-ciente a procedimento cirúrgico para desobstru-ção do uréter esquerdo - os uréteres são canais que conduzem a urina de cada um dos rins à be-xiga -, quando depois, o próprio profissional, me-diante a realização de exame mais específico (ul-trassonografia), consta-ta que o doente não tinha o rim esquerdo (agenesia renal). A culpa eviden-cia-se ainda mais quando demonstrado que o profissional deixou de levar em consideração que, dois dias antes do procedimento cirúrgico, havia sido detectada uma "exclusão renal à esquerda" no paciente, "a ser esclarecida", conforme suges-tão feita por outro profissional da área. 4. Por isso mesmo, está evidenciado o dano moral indenizá-vel, pois o sofrimento e angústia causados ao pa-ciente em razão da negligência e da imprudência do médico ultrapassaram as barreiras do mero dissabor. 4. O valor da indenização a título de dano moral deve ser fixado segundo os ditames da razoabilidade e da proporcionalidade, levando-se em consideração a condição econômica dos envolvidos, a intensidade da ofensa e a repercus-são que o evento teve na vida sócio-afetiva da ví-tima. Observados referidos parâmetros, não há por que majorar o valor arbitrado no juízo de pri-meiro grau $(\mathrm{R} \$ 15.000,00)$, como pretende o re-corrente adesivo. Agravo retido não conheci-do. Apelação cível e recurso adesivo despro-vidos (BRASIL, 2002, p. 30).

Couto Filho demonstra que:

[...] o Estado não foi prudente na preparação da defesa preventiva e vidas humanas já pagaram por esta negligência. Cogita-se aqui de sobreviver num estado de emergência, e não de se provar uma decisão de equilíbrio num conflito de interesses, visando a paz social. [...] Enquanto se vai discutir o sexo dos anjos, os cidadãos brasileiros morrerão sem cuidado, e, no Brasil, somos 36 milhões de privilegiados que gozam de planos de seguro-saúde e 134 milhões que vivem do SUS, portanto, falar em novos direitos, cidadania e justiça, direitos difusos ou sociais e não assumir suas próprias obrigações é negar a 
própria existência do Estado. Usar o tempo em intermináveis discussões preliminares poderá levar ao enterro do próprio debatedor, bastando que receba ele a visita de um mosquito (COUTO, 2002, p. 30).

Diante disso, nota-se a necessidade do avanço no que tange o acesso à justiça, a importância de zelar pelo coletivo e não pelo individual. Apesar de conseguir acesso aos tribunais, o direito não se efetiva, pelo contrário, há até mesmo violações em detrimento de decisões baseadas somente na lei e não nas nuanças dos fatos.

O que a retórica busca questionar/duvidar é a questão da justiça, nesse caso, não há que se falar em relação de sinônimo entre o Poder Judiciário e a palavra justiça, uma vez que este é considerado um precursor da injustiça, o que é paradoxo.

Justiça identificada como Judiciário é apenas um relato vencedor, sendo assim, proclamado como verdade. Mas, não é. Talvez quanto menos persistir a aniquilação do poder nas mãos do Judiciário, tal situação se inverta de um modo positivo.

\section{CONCLUSÃO}

O trabalho se propôs a analisar as três ondas de acesso à justiça do Movimento Universal de Mauro Cappelletti e Bryant Garth (1988), bem como a "quarta onda" proposta por Kim Economides (1999). A partir disso, foi destrinchada a questão econômica, sendo considerada um obstáculo de acesso à justiça na sociedade brasileira, mais especificamente, até porque não há como se ter justiça frente ao desconhecimento da lei, a morosidade processual, a pobreza, dentre outros fatores que somente fazem do acesso à justiça ser algo distante da realidade de muitos.

Ademais, a superlotação do sistema, faz com que haja uma sobrecarga dos operadores do direito e, por conta de uma cultura constituída por informação precária e pouca qualidade, faz com que muitos processos sejam arquivados e sequer concedidos direitos a quem necessita. Inclusive, como demonstrado pelo CNJ e o IPEA, 63\% dos conflitos não chegam ao judiciário, então, como resolver tal conflito? Como fazer com que o obstáculo econômico seja superado? O que seria justiça? Esses questionamentos são evidentes e de difícil solução frente ao cenário atual, uma vez que o acesso à justiça parte de um discurso vencedor que põe a justiça como essência do Poder Judiciário, o que é totalmente desconstruído por meio deste trabalho.

Ora, não há que se falar em devido processo se uma das partes não possui aptidão para discutir, para ir além do evidenciado no papel. Principalmente, quando há, por exemplo, um fator determinante como uma ação preparada por um advogado dativo. Diante disso, percebe-se que a retórica reside nesse fato, tendo em vista que mesmo o Judiciário tendo essa carga valorativa do discurso do vencedor no que tange a justiça como sua essência, é ao mesmo tempo o precursor da mais cabal das injustiças.

Portanto, é preciso modificar o modus operandi, com mais ética, para que não haja mordomia, morosidade, desídia, privilégio, dentre outros fatores que somente afastam o direito de se ter justiça dos cidadãos brasileiros.

\section{REFERÊNCIAS}

ADEODATO, João Maurício. A Retórica Constitucional. Editora Saraiva, 2009.

BOBBIO, Norberto. A Era dos Direitos. Nova ed. Rio de Janeiro: Elsevier, 2004. 
BRASIL. Constituição (1988). Constituição da República Federativa do Brasil. Brasília, DF: Senado, 2015.

BRASIL. Tribunal de Justiça do Estado de Goiás. 2 $2^{\text {a }}$ Câmara Cível. Condenado médico que operou paciente sem rim. Apelação Cível no 102322-85.2003.8.09.0093 (200391023225). Disponível em: <http://www.tjgo.jus.br/jurisprudencia/juris.php?clear=S>. Acesso em: 26 jun. 2015.

CAPPELlETTI, Mauro; GARTH, Bryant. Acesso à Justiça. Tradução de Ellen Gracie Northfleet. Porto Alegre, Fabris, 1988.

CARVALHO, José Murilo de. Cidadania no Brasil. O longo caminho. 7 ed. Rio de Janeiro: Civilização Brasileira, 2005.

CNJ - conselho nacional de justiça: $63 \%$ dos conflitos não chegam à Justiça, segundo o Ipea. Instituto de pesquisa econômica aplicada. Brasília, Distrito Federal. 27 set 2010. Disponível em: < http://www.cnj.jus.br/noticias/70216-63-dos-conflitos-nao-chegam-a-justica-segundo-o-ipea >. Acesso em: 10 jun. 2015.

COUTO, Antônio Ferreira Filho. Dengue o fato jurídico. Responsabilidade Civil do Estado. Revista Jurídica Consulex, Brasília, n. 124, p. 29-31, mar. 2002.

ECONOMIDES, Kim. Lendo as ondas do "Movimento de Acesso à Justiça": epistemologia versus metodologia?. Cidadania, Justiça e Violência. 248f. Rio de Janeiro: Editora Fundação Getúlio Vargas, 1999. Disponível em: < http://cpdoc.fgv.br/producao_intelectual/arq/39.pdf>. Acesso em: 02 jun. 2015.

JOUBERT, Joseph. O monstro estatal. Revista Direito e Cidadania. Ética: Pensar a Vida e Viver o Pensamento. 1 ed. São Paulo: Dueto, 2011.

GLOBO. Máfia das próteses coloca vidas em risco com cirurgias desnecessárias. Fantástico. <http://g1.globo.com/fantastico/noticia/2015/01/mafia-das-proteses-coloca-vidas-em-risco-comcirurgias-desnecessarias.html>. Acesso em 26 jun. 2015.

MARX, Karl; ENGELS, Friedrich. Manifesto de Partido Comunista. 1 ed. São Paulo: Expressão Popular, 2008.

SANTOS, Andre Filipe Pereira Reid. Direito e profissões jurídicas no Brasil após 1988: expansão, competição, identidades e desigualdades. 2008a. 217f. Tese (Doutorado, Programa de Pós-Graduação em Sociologia e Antropologia) - Universidade Federal do Rio de Janeiro. Rio de Janeiro, $2008 . \quad$ Disponível em: <http://www.dominiopublico.gov.br/pesquisa/DetalheObraForm.do?select_action=\&co_obra=12 4693 >. Acesso em: 13 jul. 2015.

SANTOS. Ricardo Goretti. Acesso a Justiça e Mediação: Ponderações sobre os obstáculos à efetivação de uma via alternativa de soluções de conflitos. 2008b. 266f. Dissertação (Mestrado, Programa de Pós-Graduação em Direitos e Garantias Fundamentais) - Faculdade de Direito de Vitória. Vitória, 2008. Disponível em: <http://www.fdv.br/mestrado/dissertacoes/Ricardo\%20Goretti\%20Santos.pdf>. Acesso em: 15 jul. 2015. 
SILVA. Regina Célia Bicalho Prates e. A Utilidade da Retórica. Portal de Periódicos FCLAr Unesp. Disponível em: <http://seer.fclar.unesp.br/perspectivas/article/viewFile/1486/1190>. Acesso em: 02 jun 2015.

SIMON, Schwartzman. As Causas da Pobreza. 1 ed. Rio de Janeiro: FGV, 2004. 